Regular Paper

\title{
Design of a Non-contact Electromagnetic Impact Mechanism
}

\author{
Hiroyuki HOSOKAWA ${ }^{* 1}$, Katsuhiro HIRATA ${ }^{* 1}$, Noboru NIGUCHI ${ }^{* 1}$ and Kenji OKADA ${ }^{* 1}$
}

\begin{abstract}
We have proposed a non-contact electromagnetic impact-torque mechanism (EMI mechanism) using induced current, and its characteristics have been verified by using 3-D finite element method (FEM) analysis and carrying out measurements on a prototype. This paper describes an optimization method of the parameters of the electromagnetic impact system - such as dimension and number of poles - using the Design of Experiments (DOE) method. From this result, we can obtain a design guide for constructing an efficient EMI mechanism by using the DOE method.
\end{abstract}

Keywords: induced current, finite element method, impact mechanism, current control method, design of experiments method.

(Received: 31 May 2012, Revised: 18 June 2013)

\section{Introduction}

Conventionally, impact drive mechanisms have been used in electric screwdrivers. In this mechanism, the impact torque is generated from the hammer connected to a motor beating the anvil block. In other words the kinetic energy of the motor is converted into the impact torque. Therefore, a large amount of noise is generated due to the collision between the two metal bodies.

We have proposed a non-contact electromagnetic impact torque mechanism (EMI mechanism) using induced current, and its characteristics have been verified by using 3-D finite element method (FEM) analysis and carrying out measurements on a prototype [1]-[5].

This paper describes the optimization of the proposed EMI mechanism using parametric design, which is conducted using the Design of Experiments (DOE) method. [6]

\section{Fundamental Model and Operating Principle}

\subsection{Fundamental Model and Operating Principle}

Fig. 1 shows the fundamental model of the EMI mechanism used in this study. It mainly consists of an outer rotor and an inner rotor. The inner rotor is composed of an inner core and 8 segment magnets which form 8 poles, and the outer rotor is composed of eight induction coils connected in series and an outer core made of laminated silicon steel sheets.

\subsection{Operating Principle}

Fig. 2 shows the operating principle. The segment

Correspondence: H. HOSOKAWA, Department of Adaptive Machine Systems, Graduate School of Eng., Osaka University, Yamadaoka 2-1 Suita-city, Osaka 5650871, Japan

email: hiroyuki.hosokawa@ams.eng.osaka-u.ac.jp

${ }^{*}$ Osaka University magnets and induction coils are shown as a simplified planate model. When the segment magnets are rotated, the coils cut across the magnetic flux and generate an induced current. The magnetic field then reacts with the induced current to produce a Lorentz force. At the same time the coil itself becomes an electromagnet and produces an electromagnetic force, and these 2 forces rotate the outer rotor.

\subsection{Current Control Method}

As was mentioned, the EMI mechanism's outer rotor is rotated by the Lorentz force and electromagnetic force. Therefore due to the principle of action and reaction, these forces also apply a load back onto the inner rotor. In our EMI mechanism, the impact torque is generated only when the coils are turned on, and immediately drops to zero when they are turned off.

Fig. 3 shows the current control circuit. It is divided into 2 sections: the drive circuit and the switching circuit.

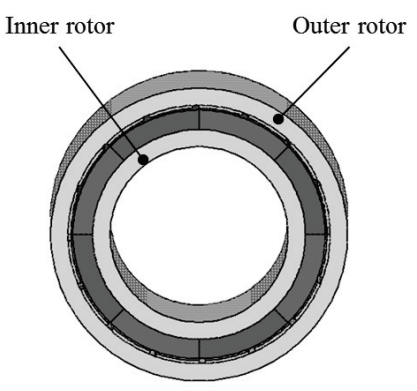

(a) Over view

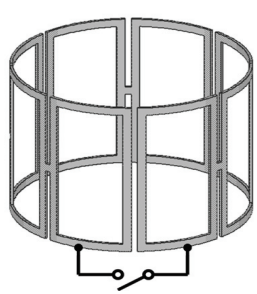

(b) Coil

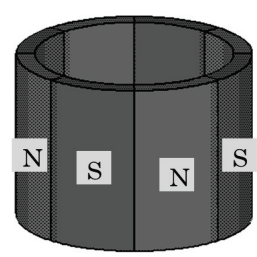

(c) Permanent magnet
Fig. 1. Fundamental Model of the EMI mechanism. 


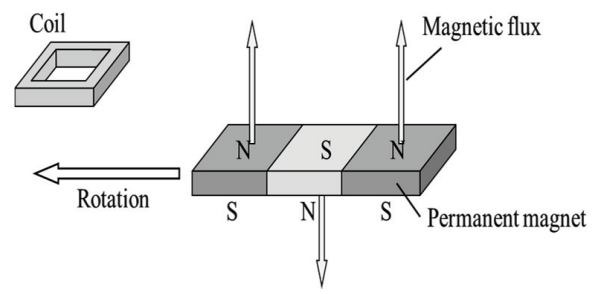

(a) Initial state

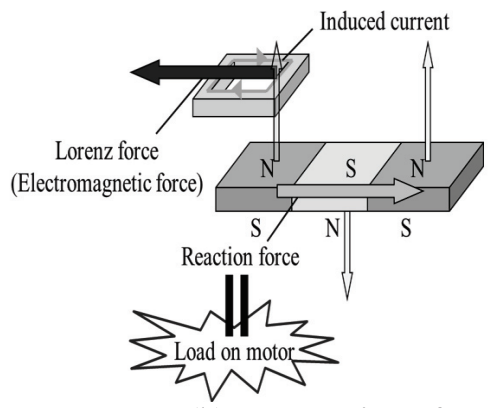

(b) Generation of each force

Fig. 2. Principle of operation.

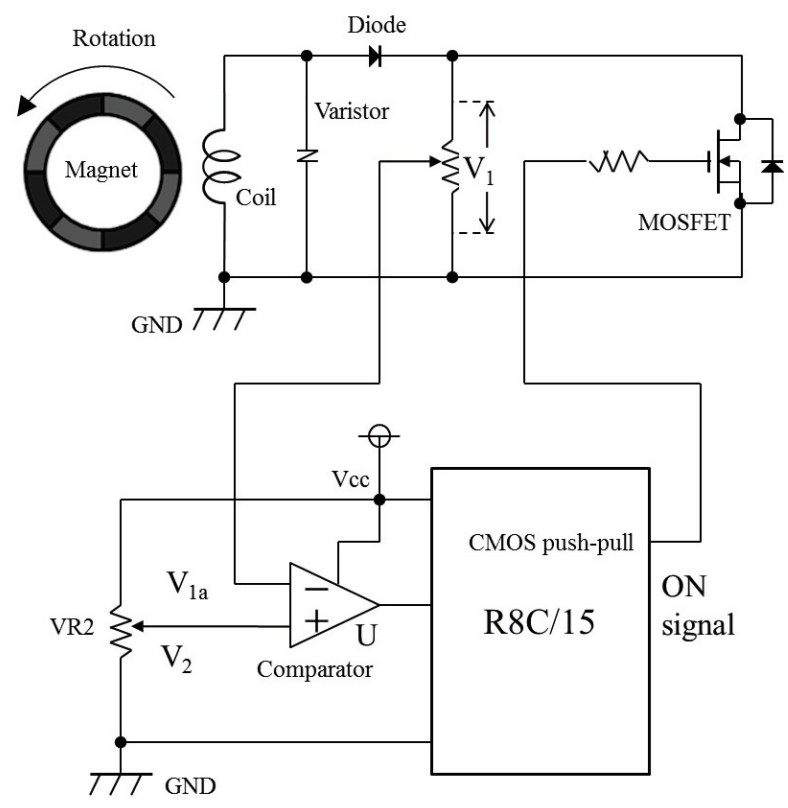

Fig. 3. Current control circuit.

\section{Characteristic Analysis and Experimental Verification}

\subsection{Characteristic Analysis}

The operating characteristics of the EMI mechanism were determined using 3-D FEM analysis. Table 1 shows the discretization data and Fig. 4 shows the 3-D mesh diagram of the analysis model. The inner rotor of the EMI mechanism is rotated at $1000 \mathrm{rpm}$ in the analysis. Then, we compared the analyzed results when the current is controlled and not controlled. The switch is closed at $3 \mathrm{~ms}$ (rotation angle of the inner rotor $=18$ $\mathrm{deg}$ ), and is opened when the torque reaches its peak value.
Fig. 5 shows the torque and induced current, and how the current control method affects the torque and induced current characteristics. As shown in Fig. 5, we can confirm that an impact torque is generated and the rise time is very short. The peak torque under current control is about $0.036 \mathrm{Nm}$, which is almost equal to the $0.037 \mathrm{Nm}$ under no control. With this control method, the maximum impact torque is preserved whilst reducing the average torque at the same time. On the other hand, the average torque was reduced $88 \%$ from $0.014 \mathrm{Nm}$ to $0.0016 \mathrm{Nm}$ by using current control. The induced current was also reduced $66 \%$, from 0.95 Arms to 0.32 Arms.

Next, Fig. 6 shows the analyzed result when the time that the switch closed was varied $3.0 \mathrm{~ms} \sim 4.3 \mathrm{~ms}$ (rotation angle of the inner rotor $=18 \sim 26 \mathrm{deg}$ ). The switch was opened when the torque reaches its peak value. As shown in Fig. 6, when the switch is closed, the torque waveform produced under current control was almost the same as the waveform produced under no control. Therefore the EMI mechanism can generate any type of torque waveform, at any timing, that is within the characteristics of the torque waveform under no control.

Additionally, Fig. 7 shows the relationship between the maximum torque and induced current generated by the rotation speed of the inner rotor. As can be seen, both the maximum torque and induced current increase proportionally to the rotation speed.

\subsection{Experimental Verification}

In order to verify the analyzed results, measurements on a prototype of the fundamental model was conducted. Figs. 8 and 9 show the prototype of the fundamental model and the impact torque measurement system respectively. The inner rotor is connected to a DC motor, and the outer rotor is connected to a torque meter and locked so as not to rotate. In the experiment, the inner rotor is driven at a constant rotation speed by the DC motor and the impact torque generated between the outer rotor and inner rotor is measured.

Fig. 10 compares the maximum torques and induced currents of the analyzed and measured results at different rotation speeds. As shown in Fig. 10, the measured results qualitatively agree with the analyzed results.

Table 1 Discretization data and CPU time CPU : Intel Core i7 950, 3.07GHz

\begin{tabular}{|c|c|}
\hline Number of elements & 934,740 \\
\hline Number of edges & $1,107,049$ \\
\hline Number of time steps & 201 \\
\hline CPU time (h) & 95 \\
\hline
\end{tabular}


Rotor core

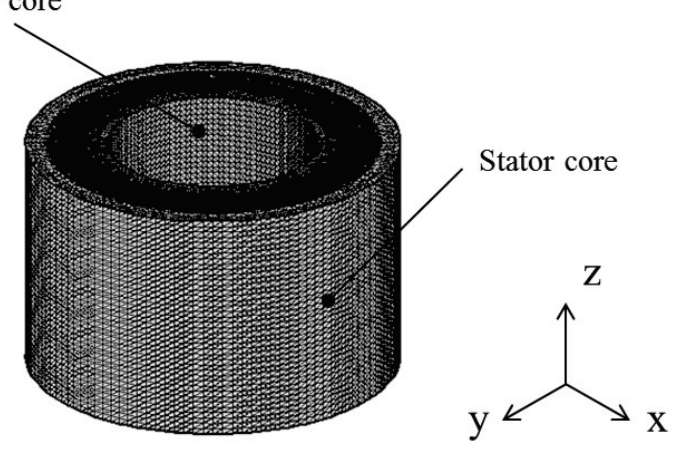

Fig. 4. 3-D mesh of the analysis model.

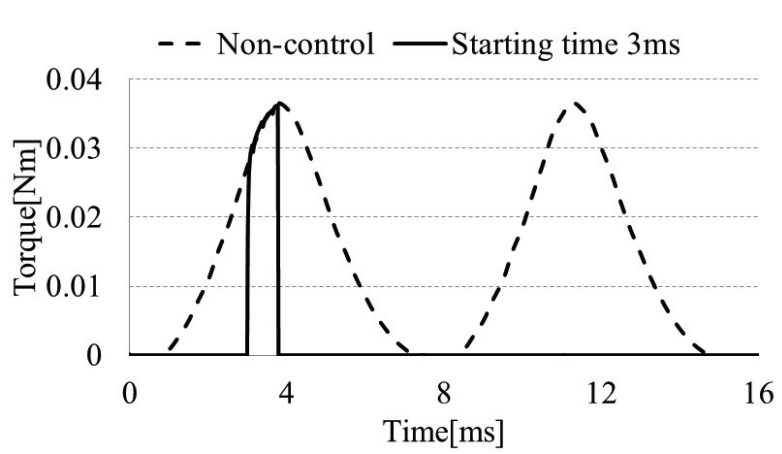

(a) Torque waveforms

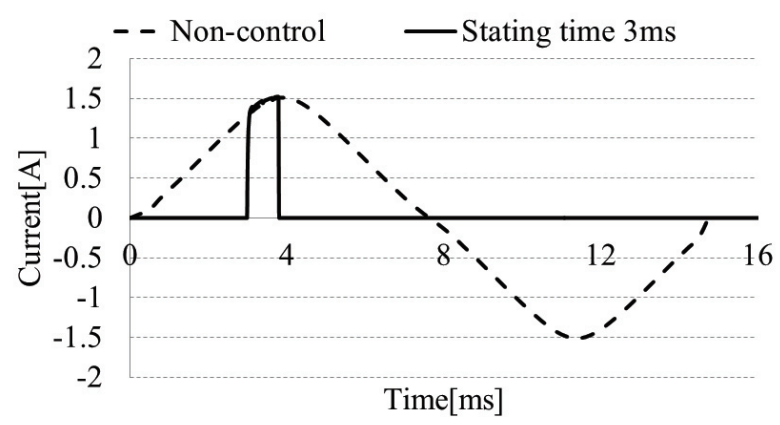

(b) Current waveforms

Fig. 5. Effect of the current control method.

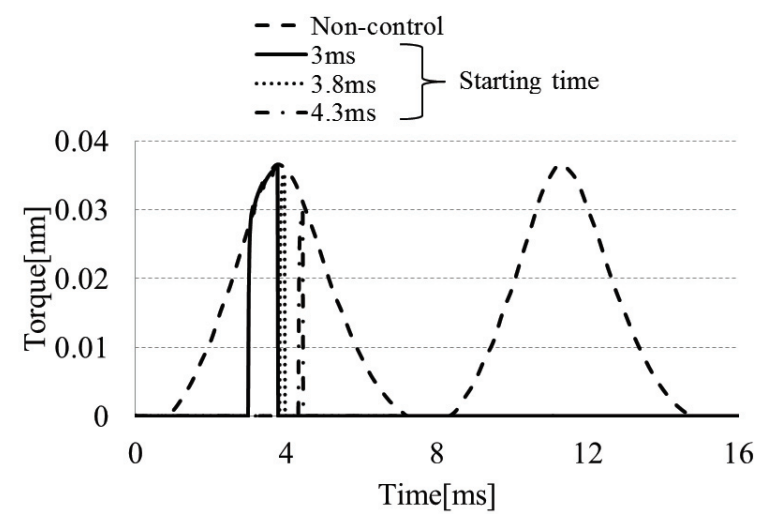

Fig. 6. Torque waveforms at different switching times.

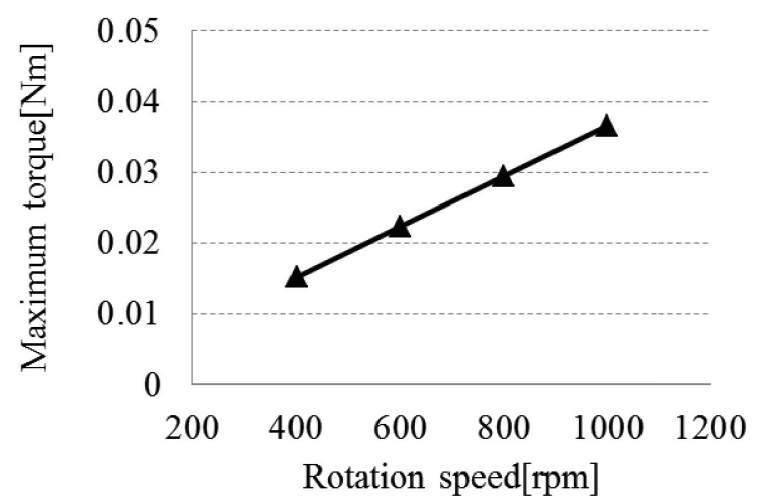

(a) Maximum torque v.s. rotation speed

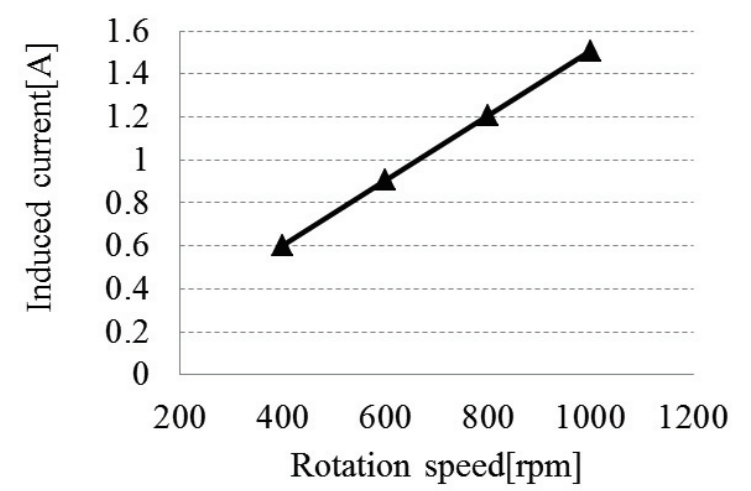

(b) Induced current when maximum torque is generated v.s. rotation speed

Fig. 7. Maximum torque and induced current v.s. rotation speed.

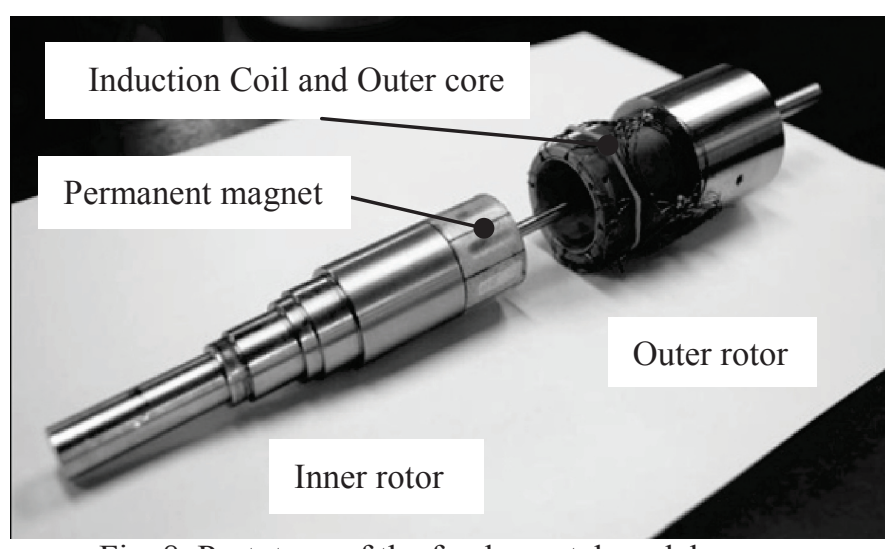

Fig. 8. Prototype of the fundamental model. 


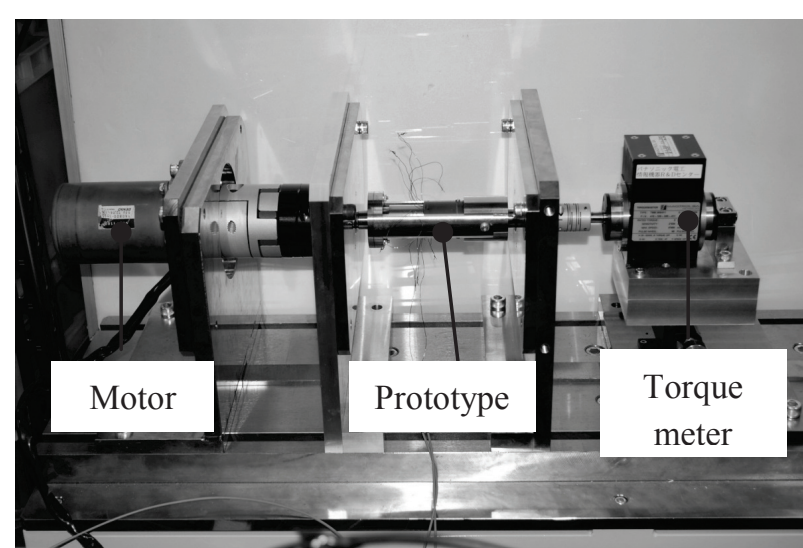

Fig. 9. Torque measuring system.

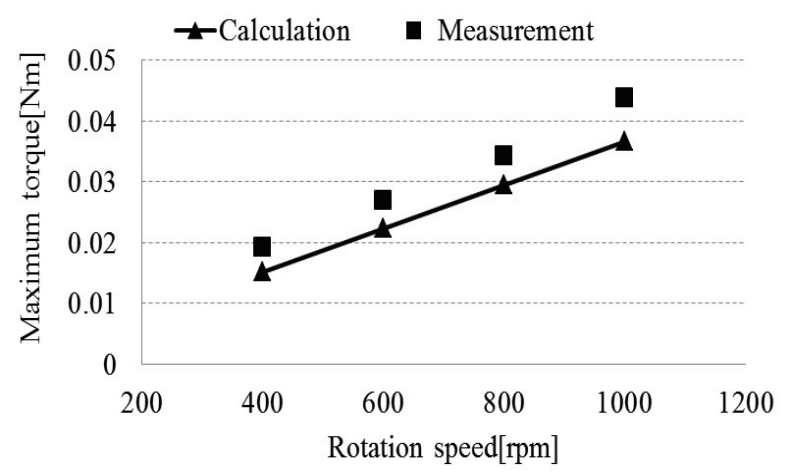

(a) Maximum torque v.s. rotation speed

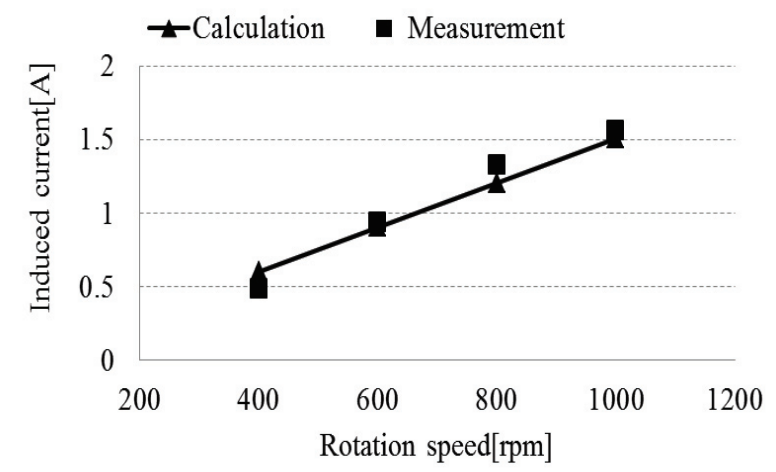

(b) Induced current v.s. rotation speed

Fig. 10. Comparison of the calculated and measured data.

\section{Optimization of the EMI Mechanism}

\subsection{Characteristic Analysis}

The current sensitivity, defined as the ratio of the maximum torque to the induced current, is calculated for evaluating the performance of the EMI mechanism, and it was used in the optimization of the EMI mechanism. However, the computational cost to vary all the parameters in the EMI mechanism is too large. Therefore, we adopted a parametric design using the design of experiments (DOE) method in order to reduce the computation time.

Table 2 shows the control factors (illustrated in Fig. 11) and levels in this study. Factor A tries to find the right balance between maintaining enough coil space (A $=30 \mathrm{~mm})$ and increasing the air gap, which will in turn also increase the torque $(A=40 \mathrm{~mm})$. Factor $B$ tries to find the right balance between increasing the magnetomotive force of the magnet $(B=A / 20)$ and keeping the magnet volume down $(B=A / 10)$. Factor $C$ tries to find the right balance between increasing the torque $(\mathrm{C}=1.30 \mathrm{~mm})$ and maintaining high manufacturability $(\mathrm{C}=1.60 \mathrm{~mm})$. Factor $\mathrm{D}$ tries to find the right balance between increasing the magnetomotive force of the coil $(D=S / 2)$ and preventing magnetic saturation of the steel from happening $(D=S / 4)$. Factor $\mathrm{F}$ tries to find the right balance between reducing the current $(\mathrm{F}=0.2 \mathrm{~mm})$ and preventing coil wire breakage $(\mathrm{F}=0.3 \mathrm{~mm})$. Factor $\mathrm{M}$ tries to find the right balance between increasing the torque $(\mathrm{M}=1.4 \mathrm{~T})$ and using slightly weaker magnets that are heat resistant $(\mathrm{M}=1.3$ $\mathrm{T})$. Then, the $\mathrm{L}_{18}$ orthogonal array shown in Table 3 was selected using the DOE method.

Fig. 12 shows the maximum torque and induced current when the inner rotor was rotated at $1000 \mathrm{rpm}$ and no current control was employed. Current control was not employed to reduce the analysis time since the maximum torque and induced current can be determined without current control. As shown in Fig. 12, the maximum torque $(2.31 \mathrm{Nm})$ of model 14 is the largest of the 18 models and the induced current $(0.44 \mathrm{~A})$ of model 1 is the smallest. Fig. 13 shows the current sensitivity of the 18 models that was obtained from the L18 orthogonal array. As shown in Fig. 13, the current sensitivity of model $14(1.53 \mathrm{Nm} / \mathrm{A})$ is the biggest.

From the analyzed results, the effect of each factor on the current sensitivity is confirmed and shown in Fig. 14. As shown in Fig. 14, all the parameters that contribute to the improvement of the current sensitivity are extracted and shown in Table 4.This new model is called the "current sensitivity emphasis" model.

In order to verify that the current sensitivity emphasis model indeed has the highest current sensitivity, it was compared with model 14 , which had the highest current sensitivity of the 18 models. As proven in Fig. 15, the current sensitivity emphasis model has a higher current sensitivity $(2.07 \mathrm{Nm} / \mathrm{A})$. Incidentally, the current sensitivity emphasis model generates a maximum torque of $2.75 \mathrm{Nm}$ and its induced current is $1.3 \mathrm{~A}$.

\subsection{Experimental Verification}

In order to verify the analyzed results using the DOE method, measurements on a prototype of the current sensitivity emphasis model was conducted. Fig. 16 compares the maximum torques and induced current of the analyzed and measured results at different rotation speeds. As shown in Fig. 16, the measured results qualitatively agree with the analyzed results. 
Table 2 Control factors and levels

\begin{tabular}{|c|c|c|c|c|}
\cline { 3 - 5 } \multicolumn{2}{c|}{} & \multicolumn{3}{c|}{ Level } \\
\hline Factor & Unit & 1 & 2 & 3 \\
\hline Magnet (M) & $\mathrm{T}$ & 1.3 & 1.4 & \\
\hline $\begin{array}{c}\text { Pole } \\
\text { number(G) }\end{array}$ & - & 4 & 6 & 8 \\
\hline Diameter(A) & $\mathrm{mm}$ & 30 & 35 & 40 \\
\hline $\begin{array}{c}\text { Magnet } \\
\text { thickness(B) }\end{array}$ & $\mathrm{mm}$ & $\mathrm{A} / 20$ & $\mathrm{~A} / 15$ & $\mathrm{~A} / 10$ \\
\hline Air gap(C) & $\mathrm{mm}$ & 1.30 & 1.45 & 1.60 \\
\hline Coil space(D) & $\mathrm{mm}$ & $\mathrm{S} / 2$ & $\mathrm{~S} / 3$ & $\mathrm{~S} / 4$ \\
\hline $\begin{array}{c}\text { Diameter } \\
\text { of coil(F) }\end{array}$ & $\mathrm{mm}$ & 0.2 & 0.25 & 0.3 \\
\hline
\end{tabular}

Table $3 \mathrm{~L}_{18}$ orthogonal array

\begin{tabular}{|c|c|c|c|c|c|c|c|c|}
\hline Number Factor & $\mathrm{M}$ & $\mathrm{G}$ & A & B & $\mathrm{C}$ & $\mathrm{D}$ & $\mathrm{F}$ & - \\
\hline 1 & 1 & 1 & 1 & 1 & 1 & 1 & 1 & 1 \\
\hline 2 & 1 & 1 & 2 & 2 & 2 & 2 & 2 & 2 \\
\hline 3 & 1 & 1 & 3 & 3 & 3 & 3 & 3 & 3 \\
\hline 4 & 1 & 2 & 1 & 1 & 2 & 2 & 3 & 3 \\
\hline 5 & 1 & 2 & 2 & 2 & 3 & 3 & 1 & 1 \\
\hline 6 & 1 & 2 & 3 & 3 & 1 & 1 & 2 & 2 \\
\hline 7 & 1 & 3 & 1 & 2 & 1 & 3 & 2 & 3 \\
\hline 8 & 1 & 3 & 2 & 3 & 2 & 1 & 3 & 1 \\
\hline 9 & 1 & 3 & 3 & 1 & 3 & 2 & 1 & 2 \\
\hline 10 & 2 & 1 & 1 & 3 & 3 & 2 & 2 & 1 \\
\hline 11 & 2 & 1 & 2 & 1 & 1 & 3 & 3 & 2 \\
\hline 12 & 2 & 1 & 3 & 2 & 2 & 1 & 1 & 3 \\
\hline 13 & 2 & 2 & 1 & 2 & 3 & 1 & 3 & 2 \\
\hline 14 & 2 & 2 & 2 & 3 & 1 & 2 & 1 & 3 \\
\hline 15 & 2 & 2 & 3 & 1 & 2 & 3 & 2 & 1 \\
\hline 16 & 2 & 3 & 1 & 3 & 2 & 3 & 1 & 2 \\
\hline 17 & 2 & 3 & 2 & 1 & 3 & 1 & 2 & 3 \\
\hline 18 & 2 & 3 & 3 & 2 & 1 & 2 & 3 & 1 \\
\hline
\end{tabular}

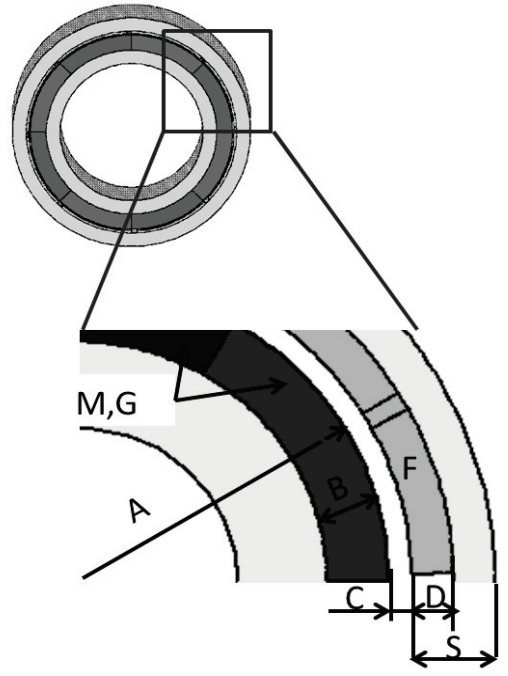

Fig. 11. Control factors.

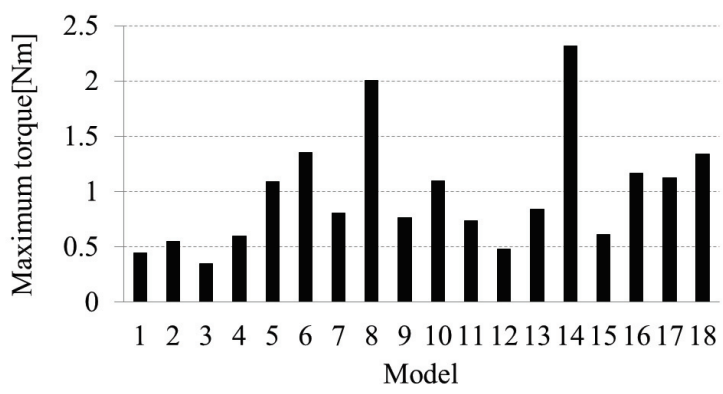

(a) Maximum torque

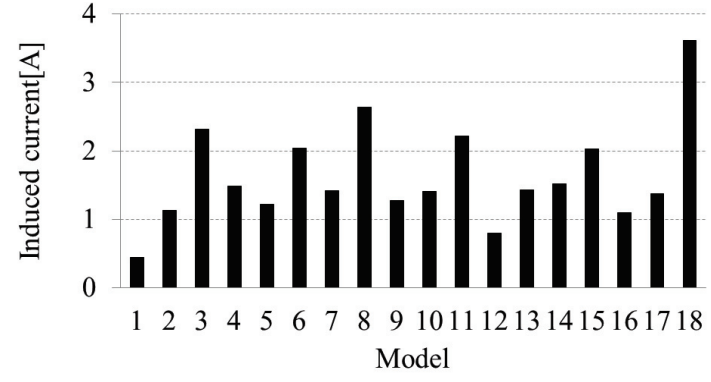

(b) Induced current when maximum torque is generated

Fig. 12. Maximum torque and induced current of the orthogonal array models.

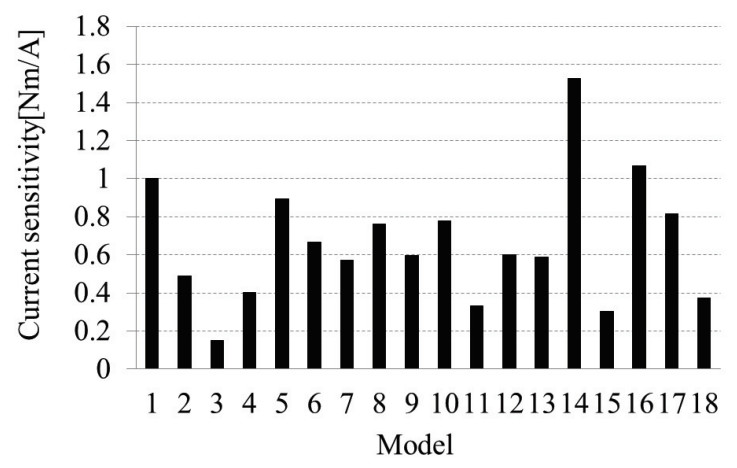

Fig. 13. Current sensitivity of the orthogonal array models. 


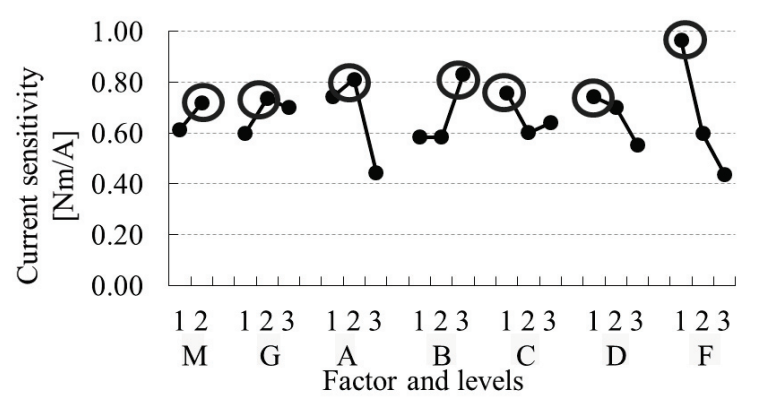

Fig. 14. Factor effect plot

Table 4 Current sensitivity emphasis model

\begin{tabular}{|c|c|c|}
\hline Factor & unit & Levels \\
\hline Magnet (M) & $\mathrm{T}$ & 1.4 \\
\hline $\begin{array}{c}\text { Pole } \\
\text { number(G) }\end{array}$ & - & 6 \\
\hline Diameter(A) & $\mathrm{mm}$ & 35 \\
\hline $\begin{array}{c}\text { Magnet } \\
\text { thickness(B) }\end{array}$ & $\mathrm{mm}$ & $\mathrm{A} / 10$ \\
\hline Air gap(C) & $\mathrm{mm}$ & 1.30 \\
\hline Coil space(D) & $\mathrm{mm}$ & $\mathrm{S} / 2$ \\
\hline $\begin{array}{c}\text { Diameter } \\
\text { of coil(F) }\end{array}$ & $\mathrm{mm}$ & 0.2 \\
\hline
\end{tabular}

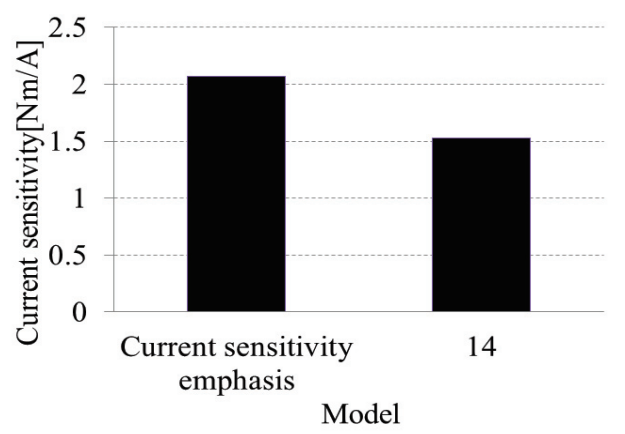

Fig. 15. Comparison of Model 14 and the current sensitivity emphasis model

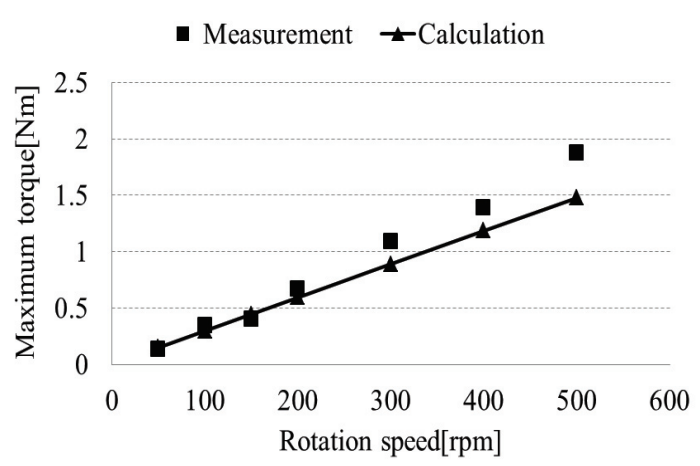

(a) Maximum torque v.s. rotation speed

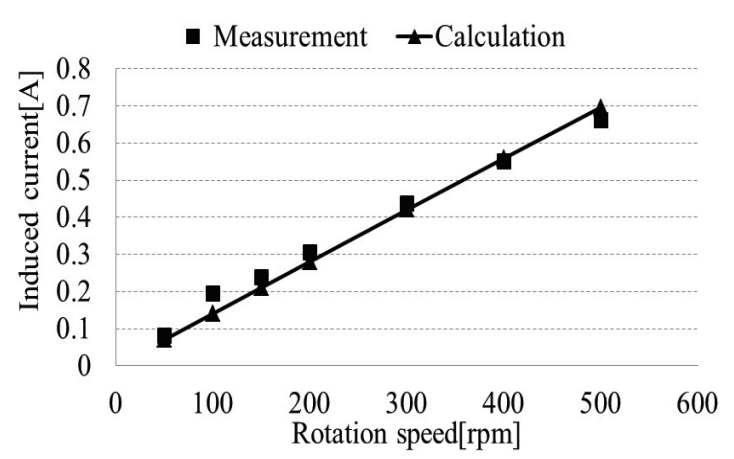

(b) Induced current when maximum torque is generated v.s. rotation speed

Fig. 16. Comparison of the calculated and measured data.

\section{Conclusion}

This paper described the validity of the current control method and current sensitivity optimization method of the EMI mechanism. The validity of the current control method was verified by using 3-D FEM analysis and carrying out measurements on a prototype. Furthermore, the sensitivity emphasis model which was obtained by using the DOE method was shown to have the highest current sensitivity. Finally, the design guide about each control parts to the improve EMI mechanism was obtained by using the DOE method.

\section{References}

[1] K. Hirata, H. Hosokawa, T. Tanibe and T. Ota, "Impact Torque Analysis of New Electromagnetic Impact Mechanism Employing 3-D Finite Element Method," IEEE Trans. Magn., Vol. 47, No. 5, pp. 1086-1089, 2011.

[2] T. Ota, Y. Mitsutake, Y. Hasegawa, K. Hirata and T. Tanaka, "Dynamic Analysis of Electromagnetic Impact Drive Mechanism Using Eddy Current," IEEE Trans. Magn., Vol. 43, No. 4, pp. 1421-1424, Apr. 2007.

[3] T. Ota, Y. Mitsutake, Y. Hasegawa, K. Hirata, T. Tanaka, Y. Kawase and T. Yamaguchi, "Transient Torque Analysis of Electromagnetic Impact Drive Mechanism Taking Into Account Motion Equation," Proc. the $16^{\text {th }}$ Biennial IEEE COMPUMAG, PA1-18, pp. 45-46, 2007.

[4] T. Yamaguchi, Y. Kawase, H. Kodama, K. Hirata, T. Ota and Y. Hasegawa, "Eddy Current Damping Analysis of Laser Marker Using 3-D Finite Element Method," IEEE Trans. Magn., Vol. 42, No. 4, pp. 1011-1014, 2006.

[5] Y. Kawase, T. Yamaguchi, S. Sano, M. Igata, K. Ida and A. Yamagiwa, "3-D Eddy Current Analysis in a Silicon Steel Sheet of an Interior Permanent Magnet Motor," IEEE Trans. Magn., Vol. 39, No. 3, pp. 1448-1451, 2003.

[6] M. S. Islam, R. Islam, T. Sebastian, A. Chandy, S. A. Ozsoylu,"Cogging Torque Minimization in PM Motors Using Robust Design Approach," IEEE Trans. Industry Appl., Vol. 47, No. 4, pp. 1661-1669, 2011. 